\title{
Gaming Disorder: How to Translate Behavioral Neuroscience Into Public Health Advances
}

\author{
Stephanie Antons ${ }^{1,2}\left(\right.$ D $\cdot$ Silke M. Müller ${ }^{1,2}$ (D) Magnus Liebherr ${ }^{1,2,3}\left(\right.$ Datthias Brand ${ }^{1,2}$ (D)
}

Accepted: 31 August 2020 / Published online: 15 September 2020

(C) The Author(s) 2020

\begin{abstract}
Purpose of Review Gaming disorder (GD), meanwhile classified as a mental disorder in both DSM-5 and ICD-11, is a current public health issue. Theoretical models assume core psychological processes, such as cue reactivity, craving, reward processing, decision-making, cognitive biases, inhibitory control, and stress relief, to be crucially involved in the development and maintenance of GD. This review summarizes neuroscientific findings on these processes in the context of GD as well as treatments and intervention programs addressing these processes.

Recent Findings We identified overlaps regarding the involvement of neural structures and networks related to psychological processes which may be targeted by public health programs. Complex interactions between executive control, salience, reward, and habit networks are crucially linked to processes involved in GD and public health programs respectively.

Summary We point at the difficulties of making one to one assignments of neural networks to psychological processes or interventions. Furthermore, new treatment and prevention programs of GD are discussed pointing at possible future directions for neuroscientific research and treatment programs for GD.
\end{abstract}

Keywords Videogaming $\cdot$ Prevention $\cdot$ Intervention $\cdot$ Neurobiology

\section{Introduction}

With the inclusion of the diagnostic criteria for Internet gaming disorder in section III of the fifth edition of the Diagnostic and Statistical Manual of mental Disorders (DSM-5) and the inclusion of gaming disorder (GD) in the 11th revision of the International Classification of Diseases (ICD-11), problematic online gaming behavior has been officially acknowledged as a disorder to which particular attention should be paid with regard to public health. Core features of GD are diminished control over the behavior, priority given to gaming, and

This article is part of the Topical Collection on Addictions

Stephanie Antons

stephanie.antons@uni-due.de

1 General Psychology: Cognition and Center for Behavioral Addiction Research (CeBAR), University of Duisburg-Essen, Forsthausweg 2, 47057 Duisburg, Germany

2 Erwin L. Hahn Institute for Magnetic Resonance Imaging, Essen, Germany

3 Department of Neuroscience, Karolinska Institute, Stockholm, Sweden continuation of gaming despite adverse consequences of gaming resulting in functional impairment [1]. Prevalence estimates vary substantially across studies but are considered as average about $9.97 \%$ ( $\mathrm{SD}=8.41$; calculated using data from the systematic review by Darvesh et al. [2]) of the general population and are considered widely similar for adults, adolescents, and children. Although the variance in prevalence estimates can be explained by methodological and cultural aspects, they show impressively that GD is a serious public health issue and that there is a need for the use and development of interventions and preventions across all ages.

Psychological processes that may be the basis for diminished control over gaming and the continuation or escalation of the behavior despite the experience of negative consequences [3] have been described in theoretical models on $\mathrm{GD}[4,5]$. Core processes assumed by both models are reward processing, decision-making, cue reactivity, craving, inhibitory control, cognitive biases, and stress relief (coping). Perceived internal and external cues are assumed to trigger conditioned cue reactivity and craving responses in terms of special attention and strong urges to play videogames. These cravings may promote decisions toward gaming (despite knowledge of potential negative side effects), especially in 
case the ability to control or inhibit affective "approach" responses toward tempting stimuli is low. The performance of the (in later stages habitualized) gaming behavior may result in rewarding outcomes in which its processing may lead to the experience of gratification or compensation. It is assumed that the experience of reward (or reduced negative mood) makes future gaming behavior more likely and, over time, may lead to distorted anticipatory reward processing in terms of cognitive biases and (maladaptive) coping styles, which in turn affect the perception and attention toward addiction-related cues. This "vicious cycle" is assumed to consolidate over time leading to (stimuli specific) reductions in inhibitory control and decision-making as well as increases in cue reactivity, craving, reward sensitivity, and cognitive biases $[4,5]$. Definitions of the central processes are summarized in Table 1.

A central assumption within the models is that these psychological processes do not stand alone but interact with each other. For example, diminished inhibitory control and decision-making abilities may increase the experience of craving in situations confronted with internal or external cues. Another example is that current stressors may act as a moderating factor that decreases control and increases affective responses (e.g., craving). Some of these psychological processes are more strongly connected, often occur simultaneously, and cannot be clearly distinguished from one another. For example, craving is often a result of the physiological, emotional, and cognitive response to conditioned stimuli of cue reactivity [9]. Another example is that reward processing is most often conceptualized as a part of decision-making [12]. Therefore, these processes are often implicitly measured together in experimental studies.

Research on substance use disorders indicates that the interactions between these psychological processes may be based on shared neural correlates and interactions between neural networks [13-15]. Similarly, a current review indicates that also in non-substance addictive behaviors including GD, similar networks are involved in different psychological processes [16]. For example, networks such as executive control (dorsomedial, dorsolateral, and ventrolateral prefrontal cortex), salience (insula, dorsal anterior cingulate cortex, inferior parietal lobulus), reward (amygdala, ventral striatum, orbitofrontal cortex, and rostral anterior cingulate cortex), and habit (caudate nucleus and putamen networks) were

Table 1 Definitions of core psychological mechanisms and their proposed involvement in the development and maintenance of gaming disorder

\begin{tabular}{|c|c|c|}
\hline $\begin{array}{l}\text { Psychological } \\
\text { mechanism }\end{array}$ & Definition in the context of addictive behaviors & Mechanisms potentially involved in GD \\
\hline $\begin{array}{l}\text { Reward } \\
\text { processing }\end{array}$ & $\begin{array}{l}\text { Neural/behavioral response to a (potentially) rewarding stimulus. } \\
\text { Comprises processing of reward-related decision outcomes } \\
\text { and anticipatory reward processing in terms of expectation of } \\
\text { gratification (see "wanting" and "liking" [6]). Also associated } \\
\text { with cue reactivity and individual reward sensitivity. }\end{array}$ & $\begin{array}{l}\text { Altered reward processing such as increased reward sensitivity } \\
\text { toward gaming rewards in early stages of GD }[4,5] \text {. In later } \\
\text { stages, there may be a shift from gratification to compensation } \\
{[4] \text {. }}\end{array}$ \\
\hline Decision-making & Preference for and choice of immediate reward [5]. & $\begin{array}{l}\text { Individuals with GD may prefer short-term rewarding gaming } \\
\text { behavior despite negative long-term consequences }[4,5] \\
\text { resulting in repeated gaming behavior. }\end{array}$ \\
\hline Cue reactivity & $\begin{array}{l}\text { Physiological, emotional, and cognitive response to conditioned } \\
\text { addiction-related stimuli }[7,8] \text {. }\end{array}$ & $\begin{array}{l}\text { Conditioning processes linking gaming behavior to reward } \\
\text { experience may result in increased responses to gaming-relatec } \\
\text { cues. Cue reactivity may trigger craving, cognitive biases, and } \\
\text { reductions in control over gaming behavior [4]. }\end{array}$ \\
\hline Craving & $\begin{array}{l}\text { Intense and urgent desire to behave in a specific way (e.g., taking } \\
\text { a substance, playing an Internet game). Is potentially the } \\
\text { consequence of cue reactivity [9]. }\end{array}$ & $\begin{array}{l}\text { Craving may increase during the development of GD. Together } \\
\text { with decreased inhibitory control and decision-making } \\
\text { abilities, craving may result in diminished control over gaming } \\
\text { behavior }[4,5] \text {. }\end{array}$ \\
\hline $\begin{array}{r}\text { Inhibitory } \\
\text { control }\end{array}$ & $\begin{array}{l}\text { Cognitive functions that enable the inhibition of prepotent } \\
\text { courses of action [10]. }\end{array}$ & $\begin{array}{l}\text { May be diminished or worsen during the development of GD } \\
\text { especially when gaming cues are present }[4,5] \text {. Resulting in an } \\
\text { imbalance between cue reactivity/craving and control } \\
\text { functions. }\end{array}$ \\
\hline Cognitive biases & $\begin{array}{l}\text { Umbrella term for different forms of biases and cognitive } \\
\text { distortions. These automatic processes, such as attentional bias } \\
\text { and approach or avoidance biases, occur when being } \\
\text { confronted with addiction-related stimuli [11•]. }\end{array}$ & $\begin{array}{l}\text { Rewarding effects of gaming behavior may lead to cognitive } \\
\text { biases, resulting in automatic processing of gaming-related } \\
\text { stimuli. Cognitive biases may enhance cue reactivity and } \\
\text { craving [4]. }\end{array}$ \\
\hline $\begin{array}{l}\text { Stress response } \\
\quad \text { (coping) }\end{array}$ & $\begin{array}{l}\text { Physiological response toward internal or external stressors, } \\
\text { which evokes the development of coping strategies }\end{array}$ & $\begin{array}{l}\text { Gaming behavior may relief from stress [5]. In addition, negative } \\
\text { consequences resulting from gaming behavior may increase } \\
\text { the experience of stress. }\end{array}$ \\
\hline
\end{tabular}


shown to be involved in processes of both inhibitory control and cue reactivity/craving (see Fig. 1a for a more detailed description of networks).

In addition, these core psychological processes have been identified as starting points for GD interventions [5, 17]. It is assumed that by treating one specific psychological process, also other psychological processes may be affected due to the existing interactions. For example, interventions aiming at increasing executive control (including inhibitory control) and decision-making capacity may reduce the experience of craving and thereby the specific gaming behavior [5]. This points to the importance of insights from the neurobiology of psychological processes involved in GD and findings on neural alterations affected by preventions and treatments for decisions on the use and development of public health programs.

The current review summarizes neuroscientific and behavioral findings on core psychological processes of GD to describe neural networks involved in these processes. Furthermore, we summarize findings from prevention and treatment studies with a special focus on neural alterations. We particularly focus on studies in the context of GD but we also included studies in which the term "Internet use disorder" is used to describe multiple online behaviors including Internet GD. Furthermore, we will reference to findings from substance use disorders to highlight promising prevention and intervention programs that have not yet been evaluated in the context of GD. A more detailed description of psychological prevention and intervention approaches can be fined in Table 2.

\section{Reward Processing and Decision-making}

\section{Neuroscientific and Psychological Findings on Reward Processing and Decision-making in GD}

Neural correlates of reward processing independent from decision making in GD has been investigated in only one study [41]. This study showed that individuals with GD and healthy controls responded similarly to monetary gains and losses. However, they report altered neural processing with regard to monetary losses within the caudate nucleus as part of the habit system.

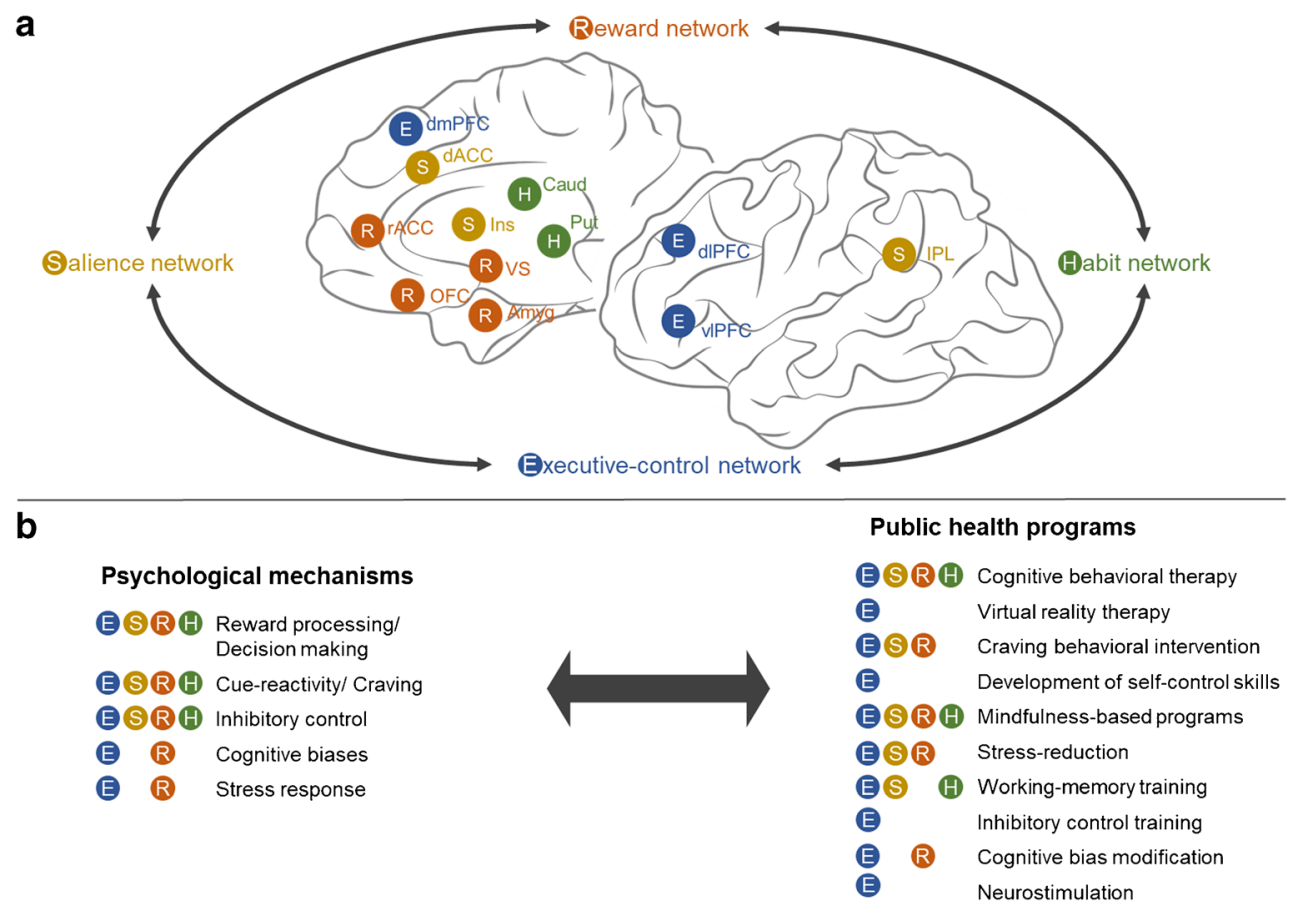

Fig. 1 The figure summarized results reviewed in the current manuscript with regard to neural networks involved in psychological processes and public health programs of gaming disorder. a Neural networks and brain regions that are assumed to be involved in the development and maintenance of gaming disorder. The figure (a) was modified from Figure 1 in Antons et al. [16]. Reprinted from Antons, S., Brand, M., and Potenza, M. N. (2020). Neurobiology of cue reactivity, craving, and inhibitory control in non-substance addictive behaviors. J Neurol Sci, 415, 116952, Copyright (2020), with permission from Elsevier. b
Preliminary findings on psychological processes and public health advances and their associated neural networks (represented by colored dots). Amyg, amygdala; Caud, caudate nucleus; dACC, dorsal anterior cingulate cortex; dlPFC, dorsolateral prefrontal cortex; dmPFC, dorsomedial prefrontal cortex; Ins, insula; IPL, inferior parietal lobe; OFC, orbitofrontal cortex; Put, putamen; rACC, rostral anterior cingulate cortex; vlPFC, ventrolateral prefrontal cortex; VS, ventral striatum 
Table 2 Description of psychological prevention and intervention approaches included in the current review

\begin{tabular}{|c|c|c|c|}
\hline Prevention/intervention & Description & Addresses & Applied in gaming disorder \\
\hline Cognitive behavioral therapy (CBT) & $\begin{array}{l}\text { Seek to help recognizing behavioral patterns and cognitions that } \\
\text { contribute to maintenance of the addictive behavior. Learning and } \\
\text { implementing skills and strategies to change these patterns of } \\
\text { behavior [18]. Often includes different modules addressing, e.g., } \\
\text { identification of triggers and discrimination of emotional states, } \\
\text { improving decision-making and providing alternative options, } \\
\text { reducing automatic thinking and cognitive distortion, enhancing } \\
\text { self-control and stress reduction. }\end{array}$ & $\begin{array}{l}\mathrm{RP} / \mathrm{DM} \\
\mathrm{CR} / \mathrm{C} \\
\mathrm{IC} \\
\mathrm{SR}\end{array}$ & {$[19-23]$; also see $[24 \bullet \bullet, 25]$} \\
\hline Virtual reality therapy & $\begin{array}{l}\text { Includes relaxation, simulation of a high-risk situation, and } \\
\text { sound-assisted cognitive reconstruction. Applied with a virtual } \\
\text { reality system and for } 8 \text { sessions [19]. }\end{array}$ & $\mathrm{CR} / \mathrm{C}$ & [19] \\
\hline Craving behavioral intervention & $\begin{array}{l}\text { Includes aspects of recognizing subjective craving, reduction of } \\
\text { craving, enhancing self-monitoring and control for craving, as well } \\
\text { as coping skill training. }\end{array}$ & $\mathrm{CR} / \mathrm{C}$ & [26-29] \\
\hline Development of self-control skills & $\begin{array}{l}\text { Part of both prevention and intervention. May include skill training on } \\
\text { self-control and self-regulation (monitoring, limit setting, time } \\
\text { management, motivation) }[30 \bullet, 31] \text {. Is often part of CBT. }\end{array}$ & $\begin{array}{l}\text { DM } \\
\text { IC }\end{array}$ & {$[30 \bullet \bullet, 31]$} \\
\hline Mindfulness-based programs & $\begin{array}{l}\text { Often includes modules on mindful awareness of gaming behavior, } \\
\text { coping with negative and enhancement of positive affective states } \\
\text { using mindfulness. Increasing craving awareness and use of } \\
\text { mindfulness to cope with craving. Stress reduction, promoting } \\
\text { acceptance of unwanted thoughts and distressing experiences. } \\
\text { Practicing of love-kindness meditation, developing a plan to use } \\
\text { mindfulness skills [32]. Is sometimes combined with other therapy } \\
\text { approaches such as reality therapy [33] and CBT. }\end{array}$ & $\begin{array}{l}\mathrm{CR} / \mathrm{C} \\
\mathrm{IC} \\
\mathrm{SR}\end{array}$ & {$[32-34]$} \\
\hline Stress reduction & $\begin{array}{l}\text { Prevention programs for GD often include modules teaching stress } \\
\text { management }[30 \bullet \bullet] \text {. Stress reduction (e.g., through meditation or } \\
\text { mindfulness relaxation) and the development of stress coping } \\
\text { strategies are often part of CBT and mindfulness-based therapies. }\end{array}$ & SR & {$[19,22,23,30 \bullet \bullet, 32-34]$} \\
\hline Working memory training & $\begin{array}{l}\text { Tasks in which individuals are asked to integrate, manipulate, } \\
\text { suppress, and prioritize information [35]. Aims at increasing } \\
\text { working memory capacity or response time to stimuli that should be } \\
\text { remembered [36, 37]. Different approaches of non-computerized, } \\
\text { computerized, and also mobile applications. }\end{array}$ & $\begin{array}{l}\mathrm{DM} \\
\mathrm{C} \\
\mathrm{IC}\end{array}$ & Pending \\
\hline Inhibitory control training & $\begin{array}{l}\text { Inhibitory control is typically trained on a go/no-go task, stop-signal } \\
\text { task, or Stroop task. In the context of addictive behaviors, these } \\
\text { inhibitory control tasks are often paired with cues related to the } \\
\text { specific addictive behavior [38]. }\end{array}$ & $\mathrm{IC}$ & Pending \\
\hline Cognitive bias modification & $\begin{array}{l}\text { Cognitive bias modification trainings aimed at changing } \\
\text { disorder-specific maladaptive cognitive motivational biases by } \\
\text { influencing disorder-specific impulsive processes [39]. }\end{array}$ & $\mathrm{CB}$ & {$[40]$} \\
\hline
\end{tabular}

$C$ craving, $C B$ cognitive bias, $C R$ cue reactivity, $D M$ decision-making, $I C$ inhibitory control, $S R$ stress response, $R P$ reward processing

When investigating reward processing in the context of decision-making, results indicate that symptoms of GD and Internet use disorders (including gaming) are associated with riskier decision-making behavior $[42,43 \bullet \bullet$. This includes a stronger preference for smaller sooner over larger later rewards (i.e., have a higher discount rate) $[44,45]$ and weaker (i.e., riskier) performance on gambling tasks that provide objective risk information $[46,47]$. In decisions under ambiguity, findings are less clear which suggests that decisionmaking performance in this type of situations might not be indicative of GD [48].

On neural levels, the preference for smaller sooner rewards (delay discounting) was associated with alterations in executive control and reward network activity in GD [49]. In risky decision-making tasks, patients with GD displayed increased activity in the left striatum, right inferior frontal gyrus, and insula. Decreased activities were found in the left superior and inferior frontal gyri and in the right precentral gyrus. Overall, the findings are in line with the results of the metaanalysis by Yao et al. [50•] showing that GD was associated with increased activity in the reward, salience, and executive control networks in the domains of reward and "cold" executive functions. Furthermore, findings on the functional activity in different phases of the decision-making process suggest that individuals with GD (compared with those without) show weaker neural responses in executive control (dorsolateral prefrontal cortex) and salience networks (inferior parietal lobule) during the evaluation of potential losses while they show 
stronger neural responses within the reward network during the processing of rewards [51].

The aforementioned findings indicate a potential neurobiological basis for why individuals suffering from GD continue gaming despite the experience of negative consequences, i.e., they have a weaker sensitivity to risk and a higher sensitivity to rewards. These neural mechanisms involving the executive control, salience, reward, and habit networks may be promising targets for developing treatments of GD [51].

\section{How to Include Techniques Improving Decision- making Into Prevention and Treatment}

Given that young people already have a risk to develop problematic gaming behaviors, prevention programs are often applied at schools. These programs address reward processing and decision-making by teaching alternative activities and goal setting, as well as understanding of media and self $[30 \bullet \cdot$. Similarly, parts of cognitive behavioral therapy (CBT) address impulsive decision-making [19,20]. The educational programs may improve decision-making in the context of gaming, although an empirical validation of this hypothesis is pending.

A combined reality therapy and mindfulness meditation program has been shown to reduce delay discounting but had no effect on risky decision-making in GD [33]. CBT has been shown to increase connectivity between the posterior cingulate cortex, cerebellum, thalamus, and occipital lingual gyrus in individuals with GD [19]. Because of the multifaceted nature of CBT, the neural mechanisms directly linked to specific techniques remain poorly understood - also for substance use disorders [18]. It may be assumed that modules on reward processing and decision-making may alter neural networks related to the processing of rewarding stimuli and executive control, which is suggested by a systematic review on neural mechanisms of CBT in depression [52]. More research is needed to understand the effects of specific interventions and prevention programs on decision-making in GD.

There is a common agreement for a relationship between working memory and decision-making [53]. Trainings increasing working memory capacity are therefore assumed to have a positive effect on decision-making. An examination of the effects of working memory training in GD is pending. However, studies reported improvements in delay discounting [54], craving [55], impulsivity, and self-regulation [56] following a working memory training in individuals with substance use disorder. In general, neural associations of traininginduced improvements of working memory have been identified within executive control, salience, and habit networks [57]. However, due to a small number of studies and methodological caveats by investigating neural correlates of working memory training, these associations should be interpreted cautiously.

\section{Cue Reactivity and Craving}

\section{Neuroscientific and Psychological Findings on Cue Reactivity and Craving in GD}

There is strong evidence that individuals with GD experience increased cue reactivity and craving on a subjective level [58]. Meta-analyses $[59,60 \bullet$ on the neurobiology of cue reactivity in addictive behaviors including GD showed that this mechanism is probably associated with hyperactivity of the precuneus, the cingulate cortex, the precentral gyrus, the right inferior frontal gyrus, the superior temporal gyrus, and the caudate nucleus - thus, within executive control, salience, and habit networks - and hypoactivities in the insula (salience network) and the postcentral gyrus. The results were partly inconsistent across the two meta-analyses as they differ regarding the inclusion of studies. Beyond cue reactivity, the first results indicate that also craving may be associated with increased activity in reward, salience, and executive control network, and habit networks in GD [61-64]. The results should be interpreted as preliminary because they base on only few studies with small sample sizes [16].

\section{How to Include Cue Reactivity Management and Craving Reduction Techniques Into Prevention and Treatment}

Since craving may develop in later stages of the development of GD [4], it is often addressed in treatment interventions and less in preventions before the onset of clear symptoms. The identification of triggers and discrimination of emotional states have been parts of CBT which reduced symptoms of GD and also gaming time [65]. Cue reactivity and craving have been also targeted in parts of virtual reality therapy and a combined CBT and bupropion treatment, which resulted in reductions of symptoms $[19,20]$. As mentioned earlier, the exact mechanisms of CBT efficacy and related mechanisms are poorly understood since modules often differ [18]. It may be assumed that modules addressing cue reactivity and craving may specifically influence networks implicated in these mechanisms such as executive control, salience, reward, and habit networks [16, 59].

Mindfulness-based interventions could also decrease the level of craving and symptom severity of GD [32, 34]. Garland and Howard [66] reviewed the effects of mindfulness meditation intervention components on behavioral and biological mechanisms in the addiction context. They conclude that mindfulness-based techniques may amplify executive control network activities, increase fronto-striatal connectivity, decrease the reactivity of the salience network, and improve autonomic regulation. These neural alterations on executive control, reward, salience, and habit networks may result in decreased cue reactivity and craving as well as reduced 
stress reactivity. Furthermore, it may result in restructuring of reward processing and increased executive function. Thus, mindfulness may not only address cue reactivity and stress reduction but also further behavioral mechanisms relevant for the treatment of GD.

The craving behavioral intervention specifically includes aspects of craving perception, detection, and coping with craving [29]. Studies indicate positive effects in terms of decreases in symptom severity, perceived craving, and game play time in GD $[26,27]$. During confrontation with cues, the intervention altered reactivity within the anterior insular as part of the salience network [29]. However, this increase in insula activity did not correlate with changes in craving [29]. The same research group investigated alterations in seed-based connectivity resulting from the intervention. Liu et al. [67] found increased connectivity between the default-mode and salience network, Zhang et al. [27] found decreased connectivity between the ventral striatum (reward network) and inferior parietal lobule (salience network), and Zhang et al. [28] found decreased resting-state connectivity between orbitofrontal cortex (reward network) and hippocampus, and between posterior cingulate cortex and the supplementary motor cortex. These results indicate that a specific craving intervention may effectively alter processing and connectivity within and between salience, reward, and executive control networks. Results should be seen as very preliminary and much more research is needed to understand the complexity of neural correlates of craving.

\section{Inhibitory Control}

\section{Neuroscientific and Psychological Findings on Inhibitory Control in GD}

Meta-analytical results point at significant impairments in inhibitory control on a behavioral level in participants with GD [68] and Internet use disorders [43, 68]. The meta-analysis by Zheng et al. [60••] identified hyperactivities within the superior temporal gyrus, the precuneus, the caudate nucleus (habit network), and the cingulate cortex (salience/reward network) as well as hypoactivities in the inferior frontal gyrus (executive control network) in individuals with GD compared with healthy controls during inhibitory control tasks. It is assumed that inhibitory control is particularly diminished when individuals are confronted with gaming-specific cues [4]. The tripartite neurocognitive model by Wei et al. [69] suggests that in such situations, the reward system overwrites the control mechanisms of the executive control system, which is amplified by the insula (salience network). Few studies investigated the neural correlates of this stimuli-specific inhibitory control in GD; however, there is first evidence for altered function of executive control, reward, salience, and habit networks in GD and further non-substance addictive behaviors [16].

\section{How to Include Inhibitory Control Techniques Into Prevention and Treatment}

Prevention programs for students often include education and skill training on self-control and self-regulation (limit setting, time management) [30•0]. As a result, e.g., Apisitwasana et al. [31] found that training focusing on the enhancement of selfregulation of gaming behavior has positive effects in terms of decreasing symptoms of GD and increased self-regulation 3 months post-intervention. In this program, teachers and parents were involved to lead activities and to help maintain consistency. Also, further educational and skill training preventions showed positive effects on self-regulation and selfrestraint of using the computer [30••]. It is possible that these changes in self-regulation may positively affect connectivity between the hippocampus and ventromedial prefrontal cortex [70]. However, this effect needs to be investigated in the context of GD.

The reduction of impulsivity, exposure training, and learning stopping techniques are parts of some cognitive behavioral programs that address inhibitory control. These treatment programs have been shown to be effective with regard to reductions in symptom severity of GD, impulsivity, and game play time $[22,23,65]$. Similarly, the combined reality therapy and mindfulness meditation approach by Yao et al. [33] specifically addresses impulsivity and showed to be effective in reducing symptoms of GD. CBT and mindfulness-based techniques may counteract neural alterations within executive control, salience, reward, and habit networks [52, 66, 71]; however, evidence from GD research is still pending.

Lee et al. [72] used transcranial direct current stimulation as a neuromodulatory technique to reduce symptoms of GD and to increase self-control in a pilot study. The stimulation over the dorsolateral prefrontal cortex as part of the executive control network resulted in decreased symptoms and game play time as well as increased self-control. This may be a promising result for the development of interventions based on noninvasive neurostimulation which has been shown to reduce craving by increasing prefrontal function and cognitive control in substance use disorders [73]. A further promising technique to increase inhibitory control may be inhibitory control training. In a meta-analysis, Jones et al. [38] report a significant decrease in food or alcohol consumption following an inhibitory control training. Its effects on neural structure and function are still unresolved. In general, preliminary findings indicate structural alterations within several regions of executive control network in children and adolescents following inhibitory control training irrespective of the addiction context [74]. Future studies may show the mechanisms potentially 
underlying positive effects of inhibitory control trainings in individuals with GD.

\section{Cognitive Biases}

\section{Neuroscientific and Psychological Findings on Cognitive Biases in GD}

Recently, evidence on cognitive biases in Internet use disorders and GD were reviewed [11•]. Four out of five studies investigating cognitive biases in GD report increased attentional and approach biases toward gaming stimuli. On a behavioral level, Zhang et al. [75] did not find these effects. However, brain regions involved in selective attention, visual processing, working memory, and cognitive control including the parts of the salience and executive control networks showed higher activity in individuals with GD as compared with control participants. Using independent component analysis, Wang et al. [76] report for the same sample increased functional connectivity between the temporal gyrus and the frontal gyrus as well as decreased connectivity between the posterior cingulate cortex, the temporal gyrus, and the frontal gyrus in individuals with GD compared with control participants. In substance use disorders, cognitive biases have been associated with an altered function within the reward, executive control and salience networks [77] which is consistent with the results on GD showing altered function within executive control and salience networks. Regarding GD, further evidence is needed to understand the neural mechanisms of cognitive biases.

\section{How to Include Techniques to Modify Cognitive Biases Into Prevention and Treatment}

The CBT for GD applied by Han et al. [22] includes one session on automatic thinking and cognitive distortion which specifically addresses cognitive biases. The intervention showed to be effective with regard to reductions in symptom severity and impulsivity; however, its effects on cognitive biases remain unclear.

Cognitive bias modification is an approach to directly address automatic biases. Only one study investigated the effects of a cognitive bias modification with regard to approach biases in GD [40]. In this study, individuals showed less approach tendencies toward gaming cues after one session of cognitive bias modification. Furthermore, the training reduced craving and intentions to game play. First, studies on neural correlates of cognitive bias modification in different psychiatric disorders indicate increases in executive control network activity and reductions in reward network activity [39]. However, these results are very preliminary and similar effects for addictive behaviors and GD are questionable.

\section{Stress Response}

\section{Neuroscientific and Psychological Findings on Stress in GD}

Studies report the symptom severity of GD to be associated with increased perceived stress [78-83] and emotional trauma or maltreatment during childhood [84, 85]. Furthermore, Canale et al. [79] could show that stress was positively correlated with hours of game play per week. As known from substance use disorder neuroscience, altered stress processing may be associated with neural alterations in the brain's stress system which includes executive control and reward networks [86]. A further study by Kaess et al. [87] showed attenuated cortisol response and more negative affect to acute stress in individuals with GD. However, results could not be replicated with hair hormone levels for cortisol $[87,88]$. These results are based on small sample sizes and should be interpreted cautiously.

As proposed for substance use disorders, interactions between response toward stressors and increased craving may be explained by interactions between the stress and reward system that lead to mechanisms of negative reinforcement and the increase in motivation to behave in a specific way [86, 89]. Consistent with this assumption, motives to play online games relating to coping and escapism as well as maladaptive cognitions relating to overvaluing game rewards were identified as predictors for GD [80, 90, 91].

\section{How to Include Stress Reduction Techniques Into Prevention and Treatment}

Stress reduction and stress control have been deployed as parts of selective intervention programs for GD and Internet use disorder to school students [30••]. In addition, reduced resilience and self-control have been identified as mediators between stress and problematic gaming behavior [79, 92], and thus might have protective effects.

Stress reduction and the development of coping strategies are often a part of CBTs. In primary studies, testing the efficacy of CBT including stress reduction techniques and the development of coping strategies have shown to decrease symptoms of GD [19, 22, 23]. Also, programs including mindfulness meditation address stress reduction and coping. In two studies, effects on symptom severity of GD were shown $[32,34]$. However, the program had no effect on cognitive coping styles [32].

These effects may be mediated by increased amygdala habituation to stress and downregulation of emotions through executive control and salience networks [93]. In addition, subjective controllability of stress may have positive effects on the development of executive control, reward, and salience networks in adolescents [94]. 


\section{Conclusion}

The review showed that research on the neuroscience of GD is still in its infancies; results and interpretation of results should be taken cautiously. Yet, the increasing findings on associations between psychological and neural mechanisms and how these could be counteracted by preventions and interventions may be used to direct and advance the development of public health programs for GD.

Overall, complex interactions between neural networks such as the executive control, salience, reward, and habit networks are the basis for different psychological mechanisms in GD. Preventions and interventions address these psychological and neural mechanisms to varying degrees. Figure $1 \mathrm{~b}$ shows which neural networks have been associated with psychological mechanisms and public health programs in previous studies. It becomes clear that a one to one assignment of neural networks to psychological processes or interventions may be impossible.

Systematic reviews on treatment approaches for GD show that CBT has been the intervention most often applied in GD and which showed the highest efficiency [24••, 25]. Although also family-based interventions and counseling programs as well as pharmacological treatments were efficient in reducing symptoms, CBT may be beneficial compared with other approaches $[24 \bullet \bullet, 25]$. Again, it has to be emphasized that much more research is needed to understand all the mechanisms involved in the development and treatment of GD. Nevertheless, it is possible that the effectiveness of CBT and similar treatments addressing multiple psychological mechanisms results from their complexity and from their effect on multiple neural networks.

In addition, less is known about the degree of involvement of different psychological mechanisms and neural alterations on an individual level. Future research may focus on the identification of biomarkers of psychological mechanisms based on neural, structure, and function as well as genetics. The identification of these biomarkers may allow to identify which intervention has an effect on whom and under which circumstances [71]. This would allow the development of more effective and possibly also personalized preventions and treatments.

\section{Code Availability Not applicable.}

Authors' Contributions SA and MB generated the focus and the structure of the article, SA, SMM, and ML performed the literature search, SA, SMM, and ML drafted the manuscript, MB supervised the writing of the manuscript and critically revised the work. The final draft was discussed with and approved by all co-authors.

Funding Open Access funding provided by Projekt DEAL. Dr. Brand reports grants from the German Research Foundation (DFG), grants from German Federal Ministry for Research and Education, grants from German Federal Ministry for Health, and grants from European Union, outside the submitted work. Dr. Brand is a member of the COST Action CA16207 "European Network for Problematic Usage of the Internet" supported by COST (European Cooperation in Science and Technology). Dr. Liebherr reports grants from the Mattias o Sonia
Westman Postdoc Stipend at the Karolinska Institutet, outside the submitted work. Dr. Müller and Dr. Antons have nothing to disclose.

Data Availability Not applicable.

\section{Compliance With Ethical Standards}

Conflicts of Interest Stephanie Antons declares that she has no conflict of interest. Silke M. Müller declares that she has no conflict of interest. Magnus Liebherr has received research funding from the Mattias o Sonia Postdoc Stipend via Karolinska Institutet. Matthias Brand has received research funding through grants from the German Research Foundation (DFG), German Federal Ministry for Research and Education, German Federal Ministry for Health, and the European Union. Dr. Brand is a member of the COST Action CA16207 "European Network for Problematic Usage of the Internet", supported by COST (European Cooperation in Science and Technology).

Open Access This article is licensed under a Creative Commons Attribution 4.0 International License, which permits use, sharing, adaptation, distribution and reproduction in any medium or format, as long as you give appropriate credit to the original author(s) and the source, provide a link to the Creative Commons licence, and indicate if changes were made. The images or other third party material in this article are included in the article's Creative Commons licence, unless indicated otherwise in a credit line to the material. If material is not included in the article's Creative Commons licence and your intended use is not permitted by statutory regulation or exceeds the permitted use, you will need to obtain permission directly from the copyright holder. To view a copy of this licence, visit http://creativecommons.org/licenses/by/4.0/.

\section{References}

Papers of particular interest, published recently, have been highlighted as:

- Of importance

- Of major importance

1. World Health Organization. International statistical classification of diseases and related health problems (11th Revision). 2019. https:// icd.who.int/browse11/1-m/en. Accessed 07.07.2019.

2. Darvesh N, Radhakrishnan A, Lachance CC, Nincic V, Sharpe JP, Ghassemi M, et al. Exploring the prevalence of gaming disorder and internet gaming disorder: a rapid scoping review. Syst Rev. 2020;9(1):68. https://doi.org/10.1186/s13643-020-01329-2.

3. Brand M, Rumpf H-J, King DL, Potenza MN, Wegmann E. Clarifying terminologies in research on gaming disorder and other addictive behaviors: distinctions between core symptoms and underlying psychological processes. Curr Opin Psychol. 2020;36:49 54. https://doi.org/10.1016/j.copsyc.2020.04.006.

4. Brand M, Wegmann E, Stark R, Müller A, Wölfling K, Robbins TW, et al. The Interaction of Person-Affect-Cognition-Execution (IPACE) model for addictive behaviors: update, generalization to addictive behaviors beyond internet-use disorders, and specification of the process character of addictive behaviors. Neurosci Biobehav Rev. 2019;104:1-10. https://doi.org/10.1016/j.neubiorev.2019.06.032.

5. Dong G, Potenza MN. A cognitive-behavioral model of internet gaming disorder: theoretical underpinnings and clinical 
implications. J Psychiatr Res. 2014;58:7-11. https://doi.org/10. 1016/j.jpsychires.2014.07.005.

6. Berridge $\mathrm{KC}$, Robinson TE. Liking, wanting and the incentivesensitization theory of addiction. Am Psychol. 2016;71(8):670-9. https://doi.org/10.1037/amp0000059.

7. Carter BL, Tiffany ST. Meta-analysis of cue-reactivity in addiction research. Addiction. 1999;94(3):327-40. https://doi.org/10.1046/j. 1360-0443.1999.9433273.x.

8. Robinson TE, Berridge KC. The psychology and neurobiology of addiction: an incentive-sensitization view. Addiction. 2000;95:91117. https://doi.org/10.1046/j.1360-0443.95.8s2.19.x.

9. Tiffany ST, Wray JM. The clinical significance of drug craving. Ann N Y Acad Sci. 2012;1248(1):1-17. https://doi.org/10.1111/j. 1749-6632.2011.06298.x.

10. Logan GD, Schachar RJ, Tannock R. Impulsivity and inhibitory control. Psychol Sci. 1997;8(1):60-4. https://doi.org/10.1111/j. 1467-9280.1997.tb00545.x.

11. Chia DXY, Zhang MWB. A scoping review of cognitive bias in Internet addiction and Internet gaming disorders. Int $\mathrm{J}$ Environ Res Public Health. 2020;17(1). https://doi.org/10.3390/ ijerph17010373. The first scoping review on cognitive biases in gaming disorder and Internet-use disorder.

12. Fellows LK. The cognitive neuroscience of human decision making: a review and conceptual framework. Behav Cogn Neurosci Rev. 2004;3(3):159-72. https://doi.org/10.1177/ 1534582304273251 .

13. Bechara A. Decision making, impulse control and loss of willpower to resist drugs: a neurocognitive perspective. Nat Neurosci. 2005;8(11):1458-63. https://doi.org/10.1038/nn1584.

14. Koob GF, Volkow ND. Neurobiology of addiction: a neurocircuitry analysis. Lancet Psychiatry. 2016;3(8):760-73. https://doi.org/10. 1016/S2215-0366(16)00104-8.

15. Zilverstand A, Huang AS, Alia-Klein N, Goldstein RZ. Neuroimaging impaired response inhibition and salience attribution in human drug addiction: a systematic review. Neuron. 2018;98(5):886-903. https://doi.org/10.1016/j.neuron.2018.03. 048.

16. Antons S, Brand M, Potenza MN. Neurobiology of cue-reactivity, craving, and inhibitory control in non-substance addictive behaviors. J Neurol Sci. 2020;415:116952. https://doi.org/10.1016/j.jns. 2020.116952.

17. Young KS, Brand M. Merging theoretical models and therapy approaches in the context of Internet gaming disorder: a personal perspective. Front Psychol. 2017;8(1853). https://doi.org/10.3389/ fpsyg.2017.01853.

18. Potenza MN, Sofuoglu M, Carroll KM, Rounsaville BJ. Neuroscience of behavioral and pharmacological treatments for addictions. Neuron. 2011;69(4):695-712. https://doi.org/10.1016/ j.neuron.2011.02.009.

19. Park SY, Kim SM, Roh S, Soh M-A, Lee SH, Kim H, et al. The effects of a virtual reality treatment program for online gaming addiction. Comput Methods Prog Biomed. 2016;129:99-108. https://doi.org/10.1016/j.cmpb.2016.01.015.

20. Kim SM, Han DH, Lee YS, Renshaw PF. Combined cognitive behavioral therapy and bupropion for the treatment of problematic on-line game play in adolescents with major depressive disorder. Comput Hum Behav. 2012;28(5):1954-9. https://doi.org/10.1016/ j.chb.2012.05.015.

21. Wölfling K, Müller KW, Dreier M, Ruckes C, Deuster O, Batra A, et al. Efficacy of short-term treatment of Internet and computer game addiction: a randomized clinical trial. JAMA Psychiatry. 2019;76(10):1018-25. https://doi.org/10.1001/jamapsychiatry. 2019.1676 .

22. Han J, Seo Y, Hwang H, Kim SM, Han DH. Efficacy of cognitive behavioural therapy for internet gaming disorder. Clin Psychol Psychother. 2020;27(2):203-13. https://doi.org/10.1002/cpp.2419.
23. González-Bueso V, Santamaría JJ, Fernández D, Merino L, Montero E, Jiménez-Murcia S, et al. Internet gaming disorder in adolescents: personality, psychopathology and evaluation of a psychological intervention combined with parent psychoeducation. Front Psychol. 2018;9(787). https://doi.org/10.3389/fpsyg.2018. 00787.

24.• King DL, Delfabbro PH, Wu AMS, Doh YY, Kuss DJ, Pallesen S, et al. Treatment of Internet gaming disorder: an international systematic review and CONSORT evaluation. Clin Psychol Rev. 2017;54:123-33. https://doi.org/10.1016/j.cpr.2017.04.002. Very comprehensive work evaluating treatments for gaming disorder.

25. Kim S, Noh D. The current status of psychological intervention research for internet addiction and internet gaming disorder. Issues Ment Health N. 2019;40(4):335-41. https://doi.org/10. 1080/01612840.2018.1534910.

26. Deng L-Y, Liu L, Xia C-C, Lan J, Zhang J-T, Fang X-Y. Craving behavior intervention in ameliorating college students' Internet game disorder: a longitudinal study. Front Psychol. 2017;8:526. https://doi.org/10.3389/fpsyg.2017.00526.

27. Zhang J-T, Ma SS, Li CR, Liu L, Xia CC, Lan J, et al. Craving behavioral intervention for Internet gaming disorder: remediation of functional connectivity of the ventral striatum. Addict Biol. 2018;23(1):337-46. https://doi.org/10.1111/adb.12474.

28. Zhang J-T, Yao Y-W, Potenza MN, Xia C-C, Lan J, Liu L, et al. Altered resting-state neural activity and changes following a craving behavioral intervention for Internet gaming disorder. Sci Rep. 2016;6(1):28109. https://doi.org/10.1038/srep28109.

29. Zhang J-T, Yao Y-W, Potenza MN, Xia CC, Lan J, Liu L, et al. Effects of craving behavioral intervention on neural substrates of cue-induced craving in Internet gaming disorder. NeuroImage Clinical. 2016;12:591-9. https://doi.org/10.1016/j.nicl.2016.09. 004.

30.• King DL, Delfabbro PH, Doh YY, Wu AMS, Kuss DJ, Pallesen S, et al. Policy and prevention approaches for disordered and hazardous gaming and internet use: an international perspective. Prevention Science. 2018;19(2):233-49. https://doi.org/10.1007/ s11121-017-0813-1. Very comprehensive systematic review on quantitative research on prevention programs for gaming disorder and Internet-use disorder.

31. Apisitwasana N, Perngparn U, Cottler LB. Effectiveness of schooland family-based interventions to prevent gaming addiction among grades 4-5 students in Bangkok, Thailand. Psychol Res Behav Manag. 2018;11:103-15. https://doi.org/10.2147/prbm.s145868.

32. Li W, Garland EL, McGovern P, O’Brien JE, Tronnier C, Howard MO. Mindfulness-oriented recovery enhancement for internet gaming disorder in U.S. adults: a stage I randomized controlled trial. Psychol Addict Behav. 2017;31(4):393-402. https://doi.org/10. 1037/adb0000269.

33. Yao Y-W, Chen P-R, Li C-SR, Hare TA, Li S, Zhang J-T, et al. Combined reality therapy and mindfulness meditation decrease intertemporal decisional impulsivity in young adults with Internet gaming disorder. Comput Hum Behav. 2017;68:210-6. https://doi. org/10.1016/j.chb.2016.11.038.

34. Li W, Garland EL, Howard MO. Therapeutic mechanisms of mindfulness-oriented recovery enhancement for internet gaming disorder: reducing craving and addictive behavior by targeting cognitive processes. J Addict Dis. 2018;37(1-2):5-13. https://doi.org/ 10.1080/10550887.2018.1442617.

35. Riddle JL, Scimeca JM, Cellier D, Dhanani S, D’Esposito M. Causal evidence for a role of theta and alpha oscillations in the control of working memory. Current Biology. 2020;30(9):1748 54.e4. https://doi.org/10.1016/j.cub.2020.02.065.

36. Constantinidis $\mathrm{C}, \mathrm{Klingberg} \mathrm{T}$. The neuroscience of working memory capacity and training. Nat Rev Neurosci. 2016;17(7):438-49. https://doi.org/10.1038/nrn.2016.43. 
37. Melby-Lervåg M, Hulme C. Is working memory training effective? A meta-analytic review. Dev Psychol. 2013;49(2):270-91. https:// doi.org/10.1037/a0028228.

38. Jones A, Di Lemma LCG, Robinson E, Christiansen P, Nolan S, Tudur-Smith $\mathrm{C}$, et al. Inhibitory control training for appetitive behaviour change: a meta-analytic investigation of mechanisms of action and moderators of effectiveness. Appetite. 2016;97:16-28. https://doi.org/10.1016/j.appet.2015.11.013.

39. Wiers RW, Gladwin TE, Hofmann W, Salemink E, Ridderinkhof KR. Cognitive bias modification and cognitive control training in addiction and related psychopathology: mechanisms, clinical perspectives, and ways forward. Clin Psychol Sci. 2013;1(2):192-212. https://doi.org/10.1177/2167702612466547.

40. Rabinovitz S, Nagar M. Possible end to an endless quest? Cognitive bias modification for excessive multiplayer online gamers. Cyberpsychol Behav Soc Netw. 2015;18(10):581-7. https://doi. org/10.1089/cyber.2015.0173.

41. Yao Y-W, Liu L, Worhunsky PD, Lichenstein S, Ma S-S, Zhu L, et al. Is monetary reward processing altered in drug-naïve youth with a behavioral addiction? Findings from internet gaming disorder. NeuroImage: Clinical. 2020;26:102202. https://doi.org/10. 1016/j.nicl.2020.102202.

42. Schiebener J, Brand M. Decision-making and related processes in internet gaming disorder and other types of Internet-use disorders. Curr Addict Rep. 2017;4(3):262-71. https://doi.org/10.1007/ s40429-017-0156-9.

43.• Ioannidis K, Hook R, Goudriaan AE, Vlies S, Fineberg NA, Grant JE, et al. Cognitive deficits in problematic internet use: metaanalysis of 40 studies. Br J Psychiatry. 2019;215:1-8. https://doi. org/10.1192/bjp.2019.3. Recet meta-analysis on cognitive deficits in problematic Internet use including gaming disorder. Significant reductions in working memory, inhibitory control, and decision making were identified.

44. Weinstein A, Abu HB, Timor A, Mama Y. Delay discounting, risktaking, and rejection sensitivity among individuals with internet and video gaming disorders. J Behav Addict. 2016;5(4):674-82. https:// doi.org/10.1556/2006.5.2016.081.

45. Wang Y, Wu L, Wang L, Zhang Y, Du X, Dong G. Impaired decisionmaking and impulse control in internet gaming addicts: evidence from the comparison with recreational internet game users. Addict Biol. 2017;22(6):1610-21. https://doi.org/10.1111/adb.12458.

46. Pawlikowski M, Brand M. Excessive internet gaming and decision making: do excessive World of Warcraft players have problems in decision making under risky conditions? Psychiatry Res. 2011;188(3):428-33. https://doi.org/10.1016/j.psychres.2011.05.017.

47. Yao Y-W, Chen P-R, Li S, Wang L-J, Zhang J-T, Yip SW, et al. Decision-making for risky gains and losses among college students with Internet gaming disorder. PloS ONE. 2015;10(1):e0116471-e. https://doi.org/10.1371/journal.pone.0116471.

48. Lin C-H, Wang C-C, Sun J-H, Ko C-H, Chiu Y-C. Is the clinical version of the Iowa Gambling Task relevant for assessing choice behavior in cases of Internet addiction? Front Psychiatry. 2019;10(232). https://doi.org/10.3389/fpsyt.2019.00232.

49. Wang Y, Wu L, Zhou H, Lin X, Zhang Y, Du X, et al. Impaired executive control and reward circuit in Internet gaming addicts under a delay discounting task: independent component analysis. Eur Arch Psychiatry Clin Neurosci. 2017;267(3):245-55. https:// doi.org/10.1007/s00406-016-0721-6.

50. Yao Y-W, Liu L, Ma S-S, Shi X-H, Zhou N, Zhang J-T, et al. Functional and structural neural alterations in internet gaming disorder: a systematic review and meta-analysis. Neurosci Biobehav Rev. 2017;83:313-24. https://doi.org/10.1016/j.neubiorev.2017. 10.029. Meta-analysis on neural alterations in gaming disorder, showing neural alteratins within fronto-striatal and fronto-cingulate circuits.
51. Liu L, Xue G, Potenza MN, Zhang J-T, Yao Y-W, Xia C-C, et al. Dissociable neural processes during risky decision-making in individuals with Internet-gaming disorder. NeuroImage: Clinical. 2017;14:741-9. https://doi.org/10.1016/j.nicl.2017.03.010.

52. Franklin G, Carson AJ, Welch KA. Cognitive behavioural therapy for depression: systematic review of imaging studies. Acta Neuropsychiatrica. 2015;28(2):61-74. https://doi.org/10.1017/neu. 2015.41.

53. Hinson JM, Jameson TL, Whitney P. Impulsive decision making and working memory. J Exp Psychol Learn Mem Cogn. 2003;29(2):298-306. https://doi.org/10.1037/0278-7393.29.2.298.

54. Bickel WK, Yi R, Landes RD, Hill PF, Baxter C. Remember the future: working memory training decreases delay discounting among stimulant addicts. Biol Psychiatry. 2011;69(3):260-5. https://doi.org/10.1016/j.biopsych.2010.08.017.

55. Bagheri Z, Abharian PH, Armani A, Taromian F, MohammadiBytamar J. Efficacy of working memory training on craving and cognitive functioning of opiate users. Clin Exp Psychol. 2018;4(04):202. https://doi.org/10.4172/2471-2701.1000202.

56. Brooks SJ, Wiemerslage L, Burch KH, Maiorana SA, Cocolas E, Schiöth HB, et al. The impact of cognitive training in substance use disorder: the effect of working memory training on impulse control in methamphetamine users. Psychopharmacology. 2017;234(12): 1911-21. https://doi.org/10.1007/s00213-017-4597-6.

57. Klingberg T. Training and plasticity of working memory. Trends Cogn Sci. 2010;14(7):317-24. https://doi.org/10.1016/j.tics.2010. 05.002.

58. Brand M, Rumpf H-J, Demetrovics Z, King DL, Potenza MN, Wegmann E. Gaming disorder is a disorder due to addictive behaviors: evidence from behavioral and neuroscientific studies addressing cue reactivity and craving, executive functions, and decisionmaking. Curr Addict Rep. 2019;6(3):296-302. https://doi.org/10. 1007/s40429-019-00258-y.

59. Starcke K, Antons S, Trotzke P, Brand M. Cue-reactivity in behavioral addictions: a meta-analysis and methodological considerations. J Behav Addict. 2018;7(2):227-38. https://doi.org/10. 1556/2006.7.2018.39.

60.• Zheng H, Hu Y, Wang Z, Wang M, Du X, Dong G. Meta-analyses of the functional neural alterations in subjects with Internet gaming disorder: similarities and differences across different paradigms. Prog Neuro-Psychopharmacol Biol Psychiatry. 2019;109656: 109656. https://doi.org/10.1016/j.pnpbp.2019.109656. Recent meta-anaysis on functional and structural neural alterations in gaming disorder withregard to cue-reactivity, executive control, and decision making.

61. Ko CH, Liu GC, Yen JY, Chen CY, Yen CF, Chen CS. Brain correlates of craving for online gaming under cue exposure in subjects with Internet gaming addiction and in remitted subjects. Addict Biol. 2011;18(3):559-69. https://doi.org/10.1111/j.13691600.2011.00405.x.

62. Liu L, Yip SW, Zhang J-T, Wang LJ, Shen ZJ, Liu B, et al. Activation of the ventral and dorsal striatum during cue reactivity in Internet gaming disorder. Addict Biol. 2017;22(3):791-801. https://doi.org/10.1111/adb.12338.

63. Wang L, Wu L, Wang Y, Li H, Liu X, Du X, et al. Altered brain activities associated with craving and cue reactivity in people with Internet gaming disorder: evidence from the comparison with recreational Internet game users. Front Psychol. 2017. https://doi.org/ 10.3389/fpsyg.2017.01150.

64. Sun YJ, Ying H, Seetohul RM, Wang XM, Ya Z, Qian L, et al. Brain fMRI study of crave induced by cue pictures in online game addicts (male adolescents). Behav Brain Res. 2012;233(2):563-76. https://doi.org/10.1016/j.bbr.2012.05.005.

65. Wölfling K, Beutel ME, Dreier M, Müller KW. Treatment outcomes in patients with internet addiction: a clinical pilot study on the effects of a cognitive-behavioral therapy program. BioMed 
Research International. 2014;2014:425924. https://doi.org/10. 1155/2014/425924.

66. Garland EL, Howard MO. Mindfulness-based treatment of addiction: current state of the field and envisioning the next wave of research. Addiction Science \& Clinical Practice. 2018;13(1):14. https://doi.org/10.1186/s13722-018-0115-3.

67. Liu L, Potenza MN, Lacadie CM, Zhang J-T, Yip SW, Xia CC, et al. Altered intrinsic connectivity distribution in internet gaming disorder and its associations with psychotherapy treatment outcomes. Addict Biol. 2020:e12917. https://doi.org/10.1111/adb. 12917.

68. Argyriou E, Davison CB, Lee TTC. Response inhibition and Internet gaming disorder: a meta-analysis. Addict Behav. 2017;71:54-60. https://doi.org/10.1016/j.addbeh.2017.02.026.

69. Wei L, Zhang S, Turel O, Bechara A, He Q. A tripartite neurocognitive model of Internet gaming disorder. Front Psychiatry. 2017;8:285. https://doi.org/10.3389/fpsyt.2017.00285.

70. Hanson JL, Gillmore AD, Yu T, Holmes CJ, Hallowell ES, Barton $\mathrm{AW}$, et al. A family focused intervention influences hippocampalprefrontal connectivity through gains in self-regulation. Child Dev. 2019;90(4):1389-401. https://doi.org/10.1111/cdev.13154.

71. Garrison KA, Potenza MN. Neuroimaging and biomarkers in addiction treatment. Curr Psychiatry Rep. 2014;16(12):513. https:// doi.org/10.1007/s11920-014-0513-5.

72. Lee SH, Im JJ, Oh JK, Choi EK, Yoon S, Bikson M, et al. Transcranial direct current stimulation for online gamers. Journal of Visualized Experiments. 2019;153. https://doi.org/10.3791/ 60007.

73. Jansen JM, Daams JG, Koeter MWJ, Veltman DJ, van den Brink W, Goudriaan AE. Effects of non-invasive neurostimulation on craving: a meta-analysis. Neuroscience \& Biobehavioral Reviews. 2013;37(10, Part 2):2472-80. https://doi.org/10.1016/j.neubiorev. 2013.07.009.

74. Delalande L, Moyon M, Tissier C, Dorriere V, Guillois B, Mevell $\mathrm{K}$, et al. Complex and subtle structural changes in prefrontal cortex induced by inhibitory control training from childhood to adolescence. Dev Sci. 2020;23(4):e12898. https://doi.org/10.1111/desc. 12898.

75. Zhang Y, Lin X, Zhou H, Xu J, Du X, Dong G. Brain activity toward gaming-related cues in internet gaming disorder during an addiction Stroop task. Front Psychol. 2016;7:714. https://doi.org/ 10.3389/fpsyg.2016.00714.

76. Wang L, Zhang Y, Lin X, Zhou H, Du X, Dong G. Group independent component analysis reveals alternation of right executive control network in Internet gaming disorder. CNS Spectr. 2018;23(5):300-10. https://doi.org/10.1017/S1092852917000360.

77. Wiers CE, Wiers RW. Imaging the neural effects of cognitive bias modification training. Neuroimage. 2017;151:81-91. https://doi. org/10.1016/j.neuroimage.2016.07.041.

78. Yen JY, Lin HC, Chou WP, Liu TL, Ko CH. Associations among resilience, stress, depression, and Internet gaming disorder in young adults. Int J Environ Res Public Health. 2019;16(17). https://doi. org/10.3390/ijerph16173181.

79. Canale N, Marino C, Griffiths MD, Scacchi L, Monaci MG, Vieno A. The association between problematic online gaming and perceived stress: the moderating effect of psychological resilience. $\mathrm{J}$ Behav Addict. 2019;8(1):174-80. https://doi.org/10.1556/2006.8. 2019.01.

80. Moudiab S, Spada MM. The relative contribution of motives and maladaptive cognitions to levels of Internet gaming disorder. Addict Behav Rep. 2019;9:100160. https://doi.org/10.1016/j. abrep.2019.100160.

81. Yu S, Mao S, Wu AMS. The interplay among stress, frustration tolerance, mindfulness, and social support in Internet gaming disorder symptoms among Chinese working adults. Asia-Pacific
Psychiatry. 2018;10(4):e12319. https://doi.org/10.1111/appy. 12319.

82. Dreier M, Wolfling K, Duven E, Giralt S, Beutel ME, Muller KW. Free-to-play: about addicted whales, at risk dolphins and healthy minnows. Monetarization design and internet gaming disorder. Addict Behav. 2017;64:328-33. https://doi.org/10.1016/j.addbeh. 2016.03.008.

83. Wong HY, Mo HY, Potenza MN, Chan MNM, Lau WM, Chui TK, et al. Relationships between severity of Internet gaming disorder, severity of problematic social media use, sleep quality and psychological distress. Int J Environ Res Public Health. 2020;17(6). https://doi.org/10.3390/ijerph17061879.

84. Kircaburun K, Griffiths MD, Billieux J. Psychosocial factors mediating the relationship between childhood emotional trauma and Internet gaming disorder: a pilot study. Eur J Psychotraumatol. 2019;10(1):1565031. https://doi.org/10.1080/20008198.2018. 1565031.

85. Bussone S, Trentini C, Tambelli R, Carola V. Early-life interpersonal and affective risk factors for pathological gaming. Front Psychiatry. 2020;11:423. https://doi.org/10.3389/fpsyt.2020. 00423.

86. Koob GF, Buck CL, Cohen A, Edwards S, Park PE, Schlosburg JE, et al. Addiction as a stress surfeit disorder. Neuropharmacology. 2014;76 Pt B:370-82. https://doi.org/10.1016/j.neuropharm.2013. 05.024.

87. Kaess M, Parzer P, Mehl L, Weil L, Strittmatter E, Resch F, et al. Stress vulnerability in male youth with Internet gaming disorder. Psychoneuroendocrinology. 2017;77:244-51. https://doi.org/10. 1016/j.psyneuen.2017.01.008.

88. Koenig J, Thaler V, Parzer P, Resch F, Kaess M. Hair hormones in male youth with Internet gaming disorder. World J Biol Psychiatry. 2019;20(4):333-8. https://doi.org/10.1080/15622975.2018. 1511921.

89. Uhl GR, Koob GF, Cable J. The neurobiology of addiction. Ann N Y Acad Sci. 2019;1451(1):5-28. https://doi.org/10.1111/nyas. 13989 .

90. Billieux J, Van der Linden M, Achab S, Khazaal Y, Paraskevopoulos L, Zullino D, et al. Why do you play World of Warcraft? An in-depth exploration of self-reported motivations to play online and in-game behaviours in the virtual world of Azeroth. Comput Hum Behav. 2013;29(1):103-9. https://doi.org/10.1016/j. chb.2012.07.021.

91. Demetrovics Z, Urban R, Nagygyorgy K, Farkas J, Zilahy D, Mervo B, et al. Why do you play? The development of the motives for online gaming questionnaire (MOGQ). Behav Res Methods. 2011;43(3):814-25. https://doi.org/10.3758/s13428-011-0091-y.

92. Jeong EJ, Ferguson CJ, Lee SJ. Pathological gaming in young adolescents: a longitudinal study focused on academic stress and self-control in South Korea. J Youth Adolesc. 2019;48(12):233342. https://doi.org/10.1007/s10964-019-01065-4.

93. Moreno-Lopez L, Ioannidis K, Askelund AD, Smith AJ, Schueler $\mathrm{K}$, van Harmelen AL. The resilient emotional brain: a scoping review of the medial prefrontal cortex and limbic structure and function in resilient adults with a history of childhood maltreatment. Biol Psychiatry Cogn Neurosci Neuroimaging. 2019;5:392-402. https://doi.org/10.1016/j.bpsc.2019.12.008.

94. Cohodes EM, Kitt ER, Baskin-Sommers A, Gee DG. Influences of early-life stress on frontolimbic circuitry: harnessing a dimensional approach to elucidate the effects of heterogeneity in stress exposure. Dev Psychobiol. 2020. https://doi.org/10.1002/dev.21969.

Publisher's Note Springer Nature remains neutral with regard to jurisdictional claims in published maps and institutional affiliations. 